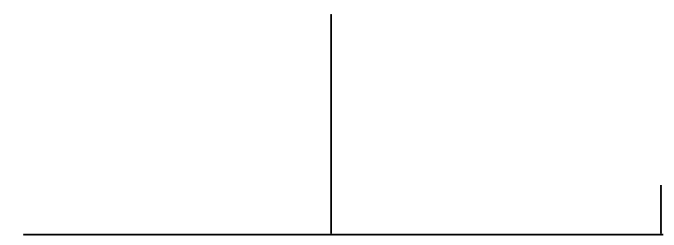

Rev. Latinoam. Psicopat. Fund., São Paulo, v. 13, n. 2, p. 253-264, junho 2010

\title{
Cuidando do cuidador: da demanda de escuta a uma escrita de si*
}

\author{
Analice de Lima Palombini \\ Rita Pereira Barboza \\ Tanise Kettermann Fick \\ Gabriel Binkowski
}

\begin{abstract}
O artigo aborda o processo de produção de narrativas escritas sobre as cenas vividas no cotidiano dos residenciais terapêticos, como registro histórico desse momento singular da reforma psiquiátrica em que trabalhadores de saúde mental e seus usuários deixam os manicômios e ocupam os residenciais. Em seus desdobramentos, investiga os efeitos produzidos pelo exercício compartilhado da escrita sobre a percepção de si e as práticas de cuidado desses trabalhadores.
\end{abstract}

Palavras-chave: Saúde mental, escrita de si, serviço residencial terapêutico, psicanálise

* Trabalho apresentado no VI Congresso Norte-Nordeste de Psicologia (CONPSI), em Belém, PA, em maio de 2009, e na Jornada do Instituto APPOA, "Psicanálise e intervenções sociais", em Porto Alegre, RS, em junho de 2009.

Grupo de pesquisa "A reinvenção das práticas de cuidado nos serviços residenciais terapêuticos: uma escrita de si". 


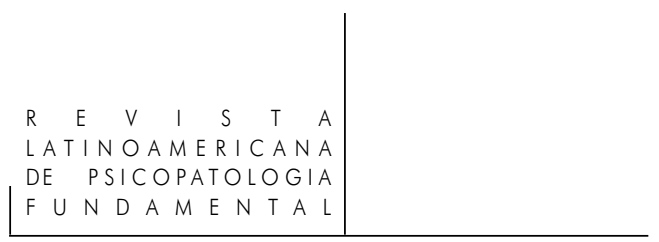

\section{Por que narrar o cotidiano? Fragmentos de um testemunho histórico...}

Os Serviços Residenciais Terapêuticos (SRTs) constituem, juntamente com os Centros de Atenção Psicossocial (CAPS), pontos cruciais da rede que se faz necessária para o êxito do processo da reforma psiquiátrica brasileira, sendo sua implantação, porém, bastante recente (Cadernos Ipub, 2006; Brasil, 2004). Conforme portaria GM 106/2000 (Brasil, 2000), os SRTs são moradias ou casas inseridas, preferencialmente, na comunidade, destinadas, prioritariamente, ao cuidado da população que, por muitos anos, viu-se alijada da sociedade, atrás dos muros dos hospitais, sem direito a habitar a cidade. A desinstitucionalização dessas pessoas, sua passagem dos pavilhões dos hospitais para as residências terapêuticas, representa um momento único na história da saúde mental no país, de que nos dão testemunho as narrativas orais que, de forma reiterada e frequente, pudemos escutar de seus trabalhadores. Pensando na importância do que se transmite por essas narrativas, concebemos a função dos testemunhos colhidos entre os trabalhadores dos SRTs como uma maneira de compartilhar, pela experiência da escrita e da leitura, um conhecimento que se tece em sua forma viva. A oferta de um espaço coletivo em que suas narrativas orais ganham forma escrita vem cumprir, nesse contexto, uma dupla função: por um lado, trata-se de estabelecer o registro e trazer a público as cenas até então inéditas do cotidiano da relação entre os trabalhadores dos residenciais e seus moradores - quando esse cotidiano não é mais o da instituição total, mas o da vida comum dos que habitam a cidade; por outro, o exercício mesmo da escrita e a sua leitura compartilhada é produtor de transformação das práticas de que se imbuem esses trabalhadores, favorecendo a invenção de novos modos de relação onde o cuidado possa ser pensado numa perspectiva outra que a da tutela herdada das práticas do internamento.

Assim, a pesquisa de que trata o presente artigo, ainda em andamento, tem como foco principal a produção de narrativas escritas sobre as experiências protagonizadas junto aos SRTs, como registro histórico, a partir de cenas do cotidiano, desse momento singular no processo da reforma, em que trabalhadores de saúde mental e seus usuários deixam os manicômios e dirigem-se aos residenciais. Em seus desdobramentos, ocupa-se de investigar os efeitos que o exercício da escrita dessas experiências e seu compartilhamento no coletivo produzem sobre as práticas de cuidado desses trabalhadores, transformando a percepção dessas mesmas experiências. 


\section{SAÚDE MENTAL}

A realização deste projeto vem contribuir para a produção de conhecimento em saúde mental, em especial no que se refere às formas do cuidado junto ao SRT que, por se tratar de equipamento recente e de caráter inovador no campo das políticas públicas de saúde, ressente-se ainda da falta de bibliografia específica sobre o tema. A contribuição abrange os dois âmbitos da investigação proposta, configurando, por um lado, registro histórico de experiências singulares que vêm acontecendo no âmbito dos SRTs e, por outro, uma reflexão crítica e aporte teórico que dê sustentação às práticas de cuidado na perspectiva da desinstitucionalização a que se propõem.

\section{Da demanda de escuta a uma escrita de si}

A experiência que aqui se apresenta traz à cena um dispositivo - a oficina de escrita - por meio do qual se tecem redes e enredos entre trabalhadores de saúde mental que atuam junto a serviços residenciais terapêuticos. Essa oficina constitui, portanto, um cuidado ofertado aos trabalhadores da atenção psicossocial e não diretamente aos seus usuários. Mas aquilo sobre o que se escreve diz respeito às experiências de cuidado, aos acontecimentos que envolvem a relação com os moradores dos residenciais terapêuticos. Assim, a rede de palavras que se vai tecendo na oficina sustenta e embala o cuidado que é ofertado a esses moradores.

Nosso contato com trabalhadores ou futuros trabalhadores dos Residenciais Terapêuticos teve início há cerca de dez anos, em experiências sucessivas de formação, assessoria e educação permanente. ${ }^{1}$ Ao longo desses anos, mesmo nos intervalos do trabalho direto com essas equipes, seguimos tendo notícias a seu respeito, acompanhando os acontecimentos muitas vezes difíceis ou desafiantes que as envolviam, que ora diziam respeito à complexidade mesma do cuidado que, no contexto das moradias, lhes era demandado, ora se reportavam às tensões e disputas no campo político em torno ao tema da reforma psiquiátrica, sendo traço marcante dessas equipes a sua implicação com a proposta dos Residenciais e sua

1. O primeiro contato ocorreu por intermédio da condução do Curso de Acompanhamento Terapêutico promovido pela Escola de Saúde Pública do RS, em que esses trabalhadores tiveram participação; a seguir, entre 2001 e 2002, através de assessoria direta à equipe que estava se constituindo para assumir o trabalho junto ao Residencial Morada São Pedro. Depois, no ano de 2007, pudemos acompanhar os trabalhadores dos dois residenciais ligados à Secretaria Estadual da Saúde do RS, Morada São Pedro e Morada Viamão, por meio de projeto de Educação Permanente realizado em parceria com a universidade. 
defesa de um projeto de desinstitucionalização da loucura, que significava a sua própria desinstitucionalização como trabalhador de saúde mental.

Desde os primeiros contatos, em especial com a equipe do Morada São Pedro, chamava atenção o seu afã de contar histórias, narrar cenas do cotidiano do Morada, compartilhar com outras pessoas as suas descobertas, entraves, alegrias. Em eventos de saúde mental em que estivemos presentes, invariavelmente, quando se abria o debate à participação do público, esses trabalhadores pediam a palavra, faziam menção às experiências de educação, supervisão ou assessoria em que nos encontráramos e contavam algum episódio ocorrido com um dos moradores do Residencial ou entre a equipe.

A proposta da oficina de escrita surgiu como acolhimento a essa vontade de narrativa, através da oferta de um espaço coletivo em que as histórias orais ganhassem forma escrita, cumprindo a dupla função a que nos referimos acima: registrar e trazer a público as cenas do cotidiano de um residencial terapêutico e favorecer a invenção e o compartilhamento de novos modos de cuidar.

Além da psicanálise, sobre a qual voltaremos adiante, a montagem do dispositivo teve como ponto de sustentação as elaborações de Walter Benjamin sobre a função da narrativa e as ideias de Michel Foucault, em torno ao tema da escrita. Enquanto Benjamin nos aponta a capacidade de narrar como condição para transmissão de uma experiência, Foucault situa a escrita como uma das técnicas próprias ao cuidado de si, cultivada, na história greco-romana, como exercício para aprender a arte de viver. Escrever, nessa acepção, vai além da função de registro para ocupar a função de experiência, de exercício, no qual se combina o já dito com a singularidade do sujeito e da circunstância. Há aqui uma profunda ligação entre teoria e prática, a escrita servindo para a ação cotidiana, e a memória sendo como um livro aberto ao qual consultar antes de planejar algo para o futuro. Como princípio de ação, a escrita passa de objeto morto à dimensão de corpo vivo.

Tais são as referências teóricas que sustentam a realização desses encontros quinzenais, chamados informalmente de "oficina" ou "laboratório" de Escrita, em que, desde setembro de 2007, trabalhadores dos Serviços Residenciais Terapêuticos Morada São Pedro e Morada Viamão reúnem-se a nós, pesquisadores e acadêmicos, para um exercício compartilhado de leitura/escrita, tendo como meta, a médio prazo, a publicação, na forma de livro, dos textos ali apresentados. Cerca de oito trabalhadores de ambos residenciais têm participado de forma regular da oficina desde o seu começo, enquanto outros mantêm uma participação assistemática ou pontual. A cada encontro, é trabalhado o texto previamente escrito por um dos participantes, por meio de leitura coletiva, comentários, correções e sugestões. Cada um dos presentes recebe uma cópia do texto e lê em voz alta um pequeno trecho, passando a palavra ao colega a seu lado, até completar uma primeira leitura integral do texto. Comentam-se, então, as impressões gerais, antes 


\section{SAÚDE MENTAL}

de passar ao trabalho de revisão linha por linha, parágrafo por parágrafo, a começar pelo título. ${ }^{2}$ Esse trabalho visa não apenas a melhor legibilidade das ideias propostas pelo autor do texto, mas o compartilhamento da experiência por ele protagonizada e sua elaboração coletiva. Não importa o grau de instrução, a profissão ou o letramento de quem escreve. O que vale é a inspiração para os textos, buscada no cotidiano de um trabalho que, referindo-se à desinstitucionalização da loucura, está longe de ser simples e comum.

\section{A escrita como experiência viva e coletiva}

O grupo iniciou de forma tímida a sua participação: durante os quatro primeiros meses de funcionamento da oficina, apenas dois textos foram escritos e apresentados naquele espaço, e a intervenção sobre os textos lidos era imputada predominantemente ao grupo de pesquisadores, identificados a um saber acadêmico. Nosso trabalho, então, nesse momento, buscava, por um lado, incentivar a escrita das histórias que invariavelmente nos eram narradas de forma oral, apesar da combinação expressa de ater-se aos textos escritos; e, por outro, fazer circular entre todos a função revisora do texto, o que, em alguns momentos, podia significar a desconstrução de um trecho, frase ou parágrafo, que na leitura se apresentava confuso, e sua reconstrução a partir da contribuição dos diferentes participantes da oficina. Rapidamente, porém, vimos crescer o volume de textos e a capacidade interventora do grupo, que parecia não mais recear a entrega de seus escritos ao coletivo, ao mesmo tempo em que perdia o pudor de imiscuir-se nos textos que um outro escrevia, mesmo quando esse outro era um dos representantes da academia (pois também submetíamos nossos textos ao grupo).

Acompanhando esse processo, assinalamos os acontecimentos e deslocamentos que foram se produzindo, dentre os quais destacamos:

1) Consideramos, desde a psicanálise (Freud, 1976 [1912], 1976 [1915]), que uma relação transferencial já instalada foi o motor que permitiu pôr em funcionamento o dispositivo da oficina. Mas, se essa relação foi o que pôs para funcionar, ela ao mesmo tempo também recebeu os efeitos desse funcionamento, de modo que o dispositivo da oficina veio transformar a transferência que o possibilitava, permitindo ao grupo realizar a sua travessia. Assim, o incremento na produção escrita e a apropriação cada vez maior da capacidade de interven-

2. A dinâmica proposta segue a experiência do laboratório de escrita do qual fomos participante no ano de 1995, conduzido pelo psicanalista José Luiz Caon. 
ção sobre os textos produzidos indicavam-nos uma operação de transferência que deixava de estar centrada em um dos pesquisadores e passava a se distribuir entre os diferentes participantes do coletivo, mutuamente implicados nessa operação. Esfumaçava-se, da mesma forma, a referência ao saber acadêmico: na lida com os textos, nós nos tornávamos testemunhas do saber que as palavras traçadas pelos trabalhadores carregam. A materialidade da escrita, o fazer circular os textos entre os participantes da oficina, foram elementos do dispositivo que nos ajudaram a sustentar essa operação em que a transferência se lateraliza.

2) A escrita como exercício de um cuidado de si mostrou-se indissociável dos processos de vida. Estes forçavam sua passagem entre as linhas do papel, emprestavam suas formas à forma do texto. É assim que, no texto escrito por Marco, sobre ser acompanhante terapêutico, uma certa passagem perdia a marca de seu estilo, claro e direto, sempre feito de frases simples. A leitura ficou truncada, as ideias confusas. As várias sugestões feitas pelos participantes da oficina na tentativa de tornar mais legível o texto não tiveram resultado. $\mathrm{Na}$ conversa, a dificuldade então se revelou: Marco queria contar-nos da importância do trabalho em equipe e de como às vezes os orgulhos atrapalham o exercício compartilhado de um cuidado, produzindo sofrimento. As palavras escritas embaralharam-se como os afetos presentificados na convivência diária entre os trabalhadores. O trabalho com o texto precisou ser retomado no encontro seguinte. No esforço de desfazer e refazer esse pedaço da escrita, era a experiência de equipe em si mesma que se refazia.

Já no texto de Beatriz, contando da passagem do hospital para o Morada e de como, nessa passagem, celebrou-se o casamento de antigos namorados que agora passavam a viver juntos, uma palavra se repetia com uma frequência que soava mal aos ouvidos: "tranquilos", era o termo de que se valia o texto para descrever a forma como o casal ia experimentando sua nova condição de vida. Beatriz recusava as sugestões de substituir o termo por outro equivalente, no intuito do grupo de evitar as repetições. Dizia "tranquilo é tranquilo mesmo". Ponto final. Foi Vera, sua colega, com muitos anos também de trabalho no hospital psiquiátrico, e profunda conhecedora das suas engrenagens, quem esclareceu o mistério: "tranquilo" remetia ao efeito tranquilizante dos medicamentos fartamente utilizados no contexto do hospital para produzir a calma esperada. "Tranquilo" era a senha que, junto com "sem intercorrências" compunha, folha por folha, os prontuários de pacientes pacificados, esvaziados de desejo em internações sem fim. A palavra, então, carregada de um sentido que nos escapara, foi mantida no texto.

3) A oficina foi se tornando uma experiência de passagem do eu ao impessoal. Para além da intensidade das lembranças individuais, foi se construindo, nessas nar- 


\section{SAÚDE MENTAL}

rativas escritas, a densidade de uma memória ao mesmo tempo pessoal e coletiva, a função autor vendo-se lançada aí, nessa báscula entre singular e coletivo, entre o nome próprio e o impessoal. O sujeito que narra, diz JeanneMarie Gagnebin (1999, p. 74), "não se restringe à afirmação da consciência de si, mas se abre a dimensões involuntárias (...), inconscientes". E, nessa abertura, "é atravessado pelas ondas de desejo, de revoltas, de desesperos coletivos". A leitura do texto de Marisa provocou essas ondas em todos nós. O texto narrava o dia em que Israel desapareceu no balneário onde o Morada Viamão havia alugado uma casa durante uma temporada de verão. Era um escrito em primeira pessoa, em que Marisa expunha seu desespero, contava de sua busca aflitiva, dos pensamentos terríveis que se interpunham à sua imaginação, dizia de sua profunda ligação com aquele morador, do sentimento maternal que a invadia e da afetação corporal que o seu sumiço lhe provocara, até o seu reencontro. A leitura compartilhada do texto fez disparar o início desse movimento de dissolução do eu e coletivização da experiência: o "eu" que o texto enunciava se distribuiu entre seus vários leitores; ao mesmo tempo que os contagiava, dissolvia-se neles. Fomos todos tocados pela intensidade dos acontecimentos narrados, e, após a primeira leitura, antes de passar ao trabalho linha por linha, muitas vozes se fizeram ouvir: para contar de outras vivências igualmente aflitivas, para compartilhar de sentimentos suscitados na relação tão próxima com os moradores de quem se cuida, para buscar compreender o que se passa nessa relação. O acontecimento narrado deslocava-se assim, da esfera do eu e, fazendo-se coletivo, possibilitava uma apreensão nova da experiência, uma outra construção de si como cuidador e outra posição de autoria em relação ao texto.

A autoria coletiva e impessoal da oficina teve emergência, de forma igualmente marcante, no trabalho em torno da grafia de uma palavra do título do texto que sua autora, Conceição, de início nomeou "Pelegrinos do amanhã". O "pele" saltava aos olhos desde a apresentação do texto. Na discussão que se seguiu imediatamente à sua leitura, a transferência para com o saber dos pesquisadores - que apontaram no título um erro ortográfico -, foi colocada em jogo. A palavra floresceu como uma multiplicidade de sentidos, vetores e afetos. Passou-se de erro ortográfico à "peleia", expressão típica dos gaúchos apontando para uma luta com "garra, com força", como salientou Beatriz, uma das trabalhadoras. A própria autora do texto jogou com sua "pele" e uma roupa de palhaço usada por ela numa manifestação ocorrida em Porto Alegre em 1990, quando alguns moradores e trabalhadores foram à rua marchar pelos direitos dos usuários de saúde mental. A mesma roupa, mais de quinze anos depois, fora vestida com orgulho por uma das moradoras do residencial numa caminhada em Bauru. Na cena, também salientaram-se outros sentidos que reforçavam o 
uso da letra "l" em vez de "r", como uma referência a Hélio Pellegrino, renomado psicanalista que, no Brasil do início dos anos 1980, trouxe à tona a discussão sobre a função social da psicanálise e denunciou o conservadorismo de suas instituições.

A "pele", de tanto burburinho - um encontro inteiro do coletivo servira apenas para a discussão do título no qual tal "erro" emergira -, acabou registrando a forma de trabalho do grupo, que buscou a solução num neologismo, "Perlegrino", mantendo, assim, abertas as possibilidades, com a circulação da palavra escrita e oral se intercalando, trazendo cenas, vozes e uma autoria de fato coletiva. Essa escolha seguiu gerando reverberações: vários meses depois, em um encontro em que se dava continuidade ao trabalho com o texto de Conceição, ao ler o seu título, uma trabalhadora falou: "Perlegrinos... acho que é por causa de tantas pernas!"

4) No desenrolar das atividades, víamos surgir elementos que, aqui e ali, em textos subsequentes, eram reafirmados, compondo e dando densidade a uma história coletiva dos residenciais e seus trabalhadores. O mesmo escrito de Conceição, de que falamos acima, foi desencadeador de um processo desse tipo. $\mathrm{O}$ texto traçava sua trajetória na reforma psiquiátrica, como um caminho semelhante ao dos atuais moradores dos residenciais: o seu desejo de mudar foi maior do que a consciência do que fazer, de modo que, de início, Conceição não fez mais do que seguir os passos de outros em um movimento para, somente aos poucos, tornar-se parte dele de forma crítica e autônoma. Logo se seguiram escritos de outros autores relatando processos semelhantes. De um a outro, foi se fazendo a trama dessa trajetória comum, coletiva, o percurso da desinstitucionalização dos trabalhadores do antigo manicômio.

O fato de algumas situações vividas serem objeto de diferentes narrativas não passou despercebido pelo grupo. Rosane, que em seu texto contava das desavenças com os homens da vila, ${ }^{3}$ por guardarem seus cavalos muito próximos das casas do Morada, empestando o ar e pisoteando os canteiros, lembrou de outros textos que se lera ali, como o de Vera, em que os cavalos faziam parte da cena narrada. Para Rosane, essa repetição, em distintas versões, era signo da veracidade do que se contava: “... é como na Bíblia, muitos apóstolos falando os mesmos fatos, aí vira verdade".

3. Vila, no Rio Grande do Sul, tem o mesmo sentido que favela. Refere-se, aqui, à Vila Cachorro Sentado, contígua ao Morada São Pedro, que não teve o benefício da regularização, como o que coube a pouco mais de quarenta famílias daquela comunidade, dentro do mesmo projeto que criou o Residencial Terapêutico. 


\section{SAÚDE MENTAL}

\section{Jogos de transferência: sujeito suposto ao saber e à política}

Para concluir, detemo-nos um pouco mais no tema da transferência no contexto do trabalho com o grupo e o modo como um psicanalista pode contar nesse contexto. Vimos que o ponto de partida da oficina, e seu elemento possibilitador, foi um vínculo já constituído entre quem a propunha e seus participantes. Esse vínculo, estabelecido por sucessivas experiências de supervisão e formação, e do exercício continuado da função de testemunha das suas histórias, é o que permitiu escutar e acolher a vontade expressa pelas equipes dos residenciais terapêuticos de narrar os acontecimentos do cotidiano do seu trabalho, compartilhando-os entre seus pares e com um público maior. É desde a transferência em operação nesse vínculo que seus trabalhadores puderam aceitar em confiança a oferta desse espaço de produção e compartilhamento de escritas. Mas esse espaço não corresponde ao campo da experiência psicanalítica stricto sensu; ele compreende, antes, o campo das ações coletivas que, no caso, diz respeito à implantação de uma política pública de saúde mental que prevê a desinstitucionalização da loucura. Assim, o sujeito suposto ao saber que a transferência requer vem pari passu com o que nos permitiremos nomear de sujeito suposto à política. É um analista-cidadão (Eric Laurent, 1999) ${ }^{4}$ o que é chamado a operar aqui, indicando, especialmente no que diz respeito às intervenções sociais, o laço indissociável entre psicanálise e política. $\mathrm{O}$ trabalho nesse contexto impõe, portanto, o reconhecimento de que, ao psicanalista, não cabe um lugar de exceção em relação às trocas sociais: o coletivo o inclui e o implica, e é preciso responder por isso.

\section{Referências}

Benjamin, W. (1933). Experiência e pobreza. In: Magia e técnica, arte e política.

Ensaios sobre literatura e história da cultura. 7. ed. São Paulo: Brasiliense, 1994. p. 114-119. (Obras escolhidas, v. 1).

4. "Os analistas têm que passar da posição de analista como especialista da desidentificação à de analista-cidadão. Um analista cidadão no sentido que tem esse termo na teoria moderna da democracia. Os analistas precisam entender que há uma comunidade de interesse entre o discurso analítico e a democracia, mas entendê-lo de verdade! Há que se passar do analista fechado em sua reserva, crítico, a um analista que participa; um analista sensível às formas de segregação; um analista capaz de entender qual foi sua função e qual lhe corresponde agora." (Laurent, 1999, p.13) 
. (1936). O narrador: considerações sobre a obra de Nikolai Leskov. In: Magia e técnica, arte e política. Ensaios sobre literatura e história da cultura. 7. ed. São Paulo: Brasiliense, 1994. p. 197-221. (Obras escolhidas, v. 1).

Brasil, Ministério da Saúde. Saúde mental no SUS: os centros de atenção psicossocial. Brasília: Ministério da Saúde, 2004.

. Ministério da Saúde. Gabinete do Ministro. Portaria n. 106, de 11 de fevereiro de 2000. Brasília: Ministério da Saúde, 2000.

Cadernos IPUB. Desinstitucionalização. A experiência dos Serviços Residenciais Terapêuticos, Rio de Janeiro, v. XII, n. 22, 2006.

Foucault, M. A escrita de si. In: Ética, sexualidade, política. Organização e seleção de textos de $\mathrm{M}$

rsitária, 2004. p. 144-162.

A vida dos homens infames. In: Estratégia, poder-saber. Organização e seleção de textos de Manoel Barros da Motta. Rio de Janeiro: Forense Universitária, 2003. p. 203-222.

O que é um autor? Lisboa: Vega/Passagens, 1992.

Freud, S. (1912). A dinâmica da transferência. In: Edição Standard Brasileira das Obras Psicológicas Completas de Sigmund Freud. Tradução da edição inglesa por Jayme Salomão. Rio de Janeiro: Imago, 1976. V. XII, p. 129-143.

. (1915). Observações sobre o amor transferencial (Novas recomendações sobre a técnica da psicanálise III). In: Edição Standard Brasileira das Obras Psicológicas Completas de Sigmund Freud. Tradução da edição inglesa por Jayme Salomão. Rio de Janeiro: Imago, 1976. V. XII, p. 205-223.

Gagnebin, J.M. História e narração em W. Benjamin. São Paulo: Perspectiva, 1999.

Laurent, E. O analista cidadão. Curinga Psicanálise e saúde mental, Belo Horizonte, n. 13, p. 12-19, 1999.

\section{Resumo}

(Caring for caregivers: from the demand for listening to writing about oneself)

This article discusses the process of writing about everyday life in therapeutic residences as a historical record of that special period in Brazilian psychiatric-care reformation when mental health workers and in-patients moved out of asylums and into therapeutic residences. This article investigates the effects of the exercise of writing about self-perception and the caring practices provided by professional caregivers.

Key words: Mental health, writing about oneself, therapeutic residences, psychoanalysis 


\section{SAÚDE MENTAL}

(Prendre soin du soignant: de la demande de l'écoute à l'écriture de soi)

Cette article analyse le processus de production de récits de situations vécues du quotidien des services de résidence thérapeutique comme registre historique de ce moment unique de la réforme psychiatrique quand les travailleurs de santé mentale et leurs patients sortent des asiles et passent à occuper les résidences. Dans cet article, nous examinons les effets produits par l'exercice partagé de l'écriture sur la perception de soi et les pratiques de soin de ces travailleurs.

Mots clés: Santé mentale, écriture de soi, service résidentiel thérapeutique, psychanalyse

(Cuidando del cuidador: de la demanda de escucha a una escrita de sí)

El artículo aborda el proceso de producción de narrativas escritas sobre las escenas vividas en lo cotidiano de las residencias terapéuticas, como registro histórico de ese momento singular de la reforma psiquiátrica en el que trabajadores de salud mental y sus usuarios dejan los manicomios y ocupan las residencias terapéuticas. En sus desdoblamientos, investiga los efectos producidos por el ejercicio compartido de la escritura sobre la percepción de sí y las prácticas de cuidado de estos trabajadores.

Palabras claves: Salud mental, escrita de sí, servicio residencial terapéutico, psicoanálisis

Citação/Citation: Palombini, A.L.; Barboza, R.P.; Fick, T.K.; Binkowski, G. Cuidando do cuidador: da demanda de escuta a uma escrita de si. Revista Latinoamericana de Psicopatologia Fundamental, São Paulo, v. 13, n. 2, p. 253-264, jun. 2010.

Editor do artigo/Editor: Profa. Dra. Ana Cristina Figueiredo

Recebido/Received: 29.3.2010 / 3.29.2010 Aceito/Accepted: 26.4.2010 / 4.26.2010

Copyright: () 2009 Associação Universitária de Pesquisa em Psicopatologia Fundamental/ University Association for Research in Fundamental Psychopathology. Este é um artigo de livre acesso, que permite uso irrestrito, distribuição e reprodução em qualquer meio, desde que $\mathrm{o}$ autor e a fonte sejam citados/This is an open-access article, which permits unrestricted use, distribution, and reproduction in any medium, provided the original author and source are credited.

Financiamento/Funding: Os autores declaram não terem sido financiados ou apoiados/The authors have no support or funding to report.

Conflito de interesses/Conflict of interest: Os autores declaram que não há conflito de interesses/The authors declare that has no conflict of interest. 


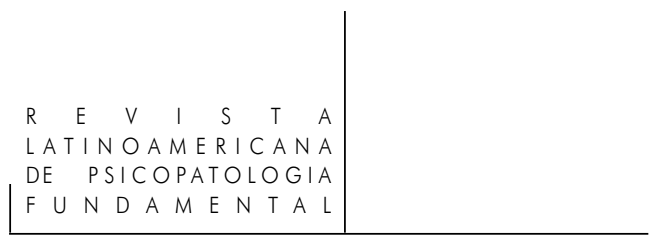

\section{Analice de Lima Palombini}

Doutora em Saúde Coletiva pela Universidade do Estado do Rio de Janeiro - UERJ (Rio de Janeiro, RJ, Brasil); mestre em Filosofia pela Universidade Federal do Rio Grande do Sul - UFRGS (Porto Alegre, RS, Brasil); docente do Instituto de Psicologia da Universidade Federal do Rio Grande do Sul - UFRGS.

Av. Jerônimo de Ornelas, 651/11 - Santana

90040-341 Porto Alegre, RS, Brasil

Fone: (51) 3779-0272

e-mail: analicepalombini@ufrgs.br

\section{Rita Pereira Barboza}

Estudante de graduação em psicologia da Universidade Federal do Rio Grande do Sul UFRGS (Porto Alegre, RS, Brasil); bolsista de iniciação científica Propesq/UFRGS.

Rua Costa Lima, 447 - Nonoai

91720-480 Porto Alegre, RS, Brasil

Fone: (51) 3266-1804

e-mail: ritapereirabarboza@gmail.com

\section{Tanise Kettermann Fick}

Residente em Saúde Mental Coletiva da Universidade Federal do Rio Grande do Sul UFRGS (Porto Alegre, RS, Brasil); psicóloga.

Rua José do Patrocínio, 693/103 - Cidade Baixa

90050-003 Porto Alegre, RS, Brasil

Fone: (51) 9616-0633

e-mail: taniseke@gmail.com.br

\section{GabriEl BinkowsKi}

Residente em Saúde Mental Coletiva da Universidade Federal do Rio Grande do Sul UFRGS (Porto Alegre, RS, Brasil); psicólogo.

Rua Felicíssimo de Azevedo, 473/103 - Higienópolis

90540-110 Porto Alegre, RS, Brasil

Fone: (51) 3342-5397

e-mail: gabriel.binkowski@gmail.com 